\title{
A LEITURA FORMADORA: DA RETENÇÃO DOS RECURSOS LINGÜÍSTICOS À CONSTRUÇÃO DA REALIDADE
}

\begin{abstract}
Mariusa Gasparino Romano*
Resumo: Neste diário, apresento uma possibilidade de se proceder à leitura dos clássicos em sala de aula, no ensino médio. Os resultados foram muito significativos, tendo em vista o fato de que os alunos tendem a repudiar este tipo de leitura.
\end{abstract}

Palavras-Chave: Ensino, Leitura, Clássicos da Literatura.

\section{Introdução}

As reflexões, os estudos sobre alfabetização têm avançado no sentido de apontar, aos educadores, novos aspectos a considerar: desde concepções que partem de uma visão de escola realmente democrática (no que se refere ao acesso e permanência do trabalho oferecido a todos), passando pela consideração detalhada do desenvolvimento da criança, até refletir uma concepção de avaliação predominantemente diagnóstica e formativa que assessora o fazer pedagógico do professor. Esse caminhar mais cuidadoso revê o papel da afetividade, bem como as intervenções cognitivas que podem perpassar a sala de aula, apontando para novos rumos metodológicos que configurem uma outra noção de processo de ensino-aprendizagem. Essa noção de alfabetização integra as contribuições e os aprofundamentos dados por diversas áreas do conhecimento: Psicologia, Filosofia, Lingüística, Sociologia, Didática, História entre outras.

Alguns estudiosos como Soares (2001) e Ferreiro (1990), além de publicações norteadoras, dentre as quais ressaltamos os Parâmetros Curriculares Nacionais -PCN(BRASIL, 1998), têm apontado a necessidade de ir além da aquisição de uma tecnologia para aprender a ler e a escrever e investem, antes de qualquer coisa, na necessidade de formar um cidadão que participe de um mundo letrado.

A alfabetização que satisfaça às necessidades educacionais atuais deveria permitir ao sujeito literalmente "fazer uso da palavra" expressando-se, interagindo e conquistando

Professora efetiva da rede municipal de ensino de São José dos Campos/SP. Assessora do Serviço de Orientação Educacional do Ensino Fundamental da Secretaria Municipal de Educação de São José dos Campos. Mestre em Linguística Aplicada. 
seu real valor de cidadão. "Fazer uso da palavra", seja ela escrita ou oral, prevê resgatar e apropriar-se dos usos sociais da língua, contemplando as funções de ação da mesma na sociedade. Isso nos faz rever a tradicional concepção de alfabetização que entende leitura e escrita a partir da decomposição e decifração de frases, palavras e sílabas.

Para Carvalho (2002, p.6), apesar dos avanços teóricos, até hoje:

Os índices de alfabetização são medidos simplesmente pela capacidade de decifrar sinais lingüísticos, o que não garante ao indivíduo a vantagem de não se perder pois saber decodificar não quer dizer saber utilizar a leitura em proveito próprio e do outro. Estar alfabetizado, é apenas não precisar de escribas e intérpretes para produzir e compreender discursos, não é qualidade fundamental para penetrar no mundo da escrita.

Talvez aí tenha se constatado o sentido mais amplo da alfabetização: a idéia de letramento que Soares (2001) define como algo mais que a aquisição da "tecnologia de ler e escrever"; um estado ou condição que um grupo social (ou um indivíduo) adquire como consequiência de ter se apropriado dessas habilidades. Digamos que letramento é o diferencial que se dá ao indivíduo decorrente de sua apropriação da escrita e da leitura.

Parece-nos que as tendências apontam para muito mais que alfabetização (ainda que não tenhamos conquistado a essência desta nos escores brasileiros); o ideal seria alfabetizar letrando. E é neste contexto que os PCN (BRASIL, 1998) sugerem um novo investimento: a construção da oralidade.

Como se daria a construção da oralidade?

Em primeiro lugar, percebemos que, quanto mais a prática escolar "imitar" a prática social e diária do sujeito sobre a leitura e a escrita (operando sobre elas para construir significados reais), mais chances ele terá de se apropriar do uso real e prático dos diversos portadores de gêneros discursivos que a sociedade tem disponível. Ao operar ativamente sobre esses portadores, construirá sua oralidade a partir do referencial de apoio das diversas características que os mesmos oferecem.

É sobre essa oralidade contemplada por recursos lingüísticos de diferentes gêneros discursivos que se edifica uma produção oral e textual também rica desses recursos, que permita ao sujeito ir além da alfabetização decifratória para caminhar em direção ao significado que o letramento sustenta. (BRASIL, 1998)

Segundo Silva (1983), ainda nos primórdios das reflexões lingüísticas, já se concebe o papel ativo e criativo do sujeito frente às regras gramaticais, já se concebe o processo de elaboração diante da oralidade e escrita.

E assim, tendo em vista o processo de elaboração da oralidade, temos, de um lado temos a presença das estruturas textuais, dos recursos lingüísticos e das regras gramaticais, de outro, os diversos gêneros discursivos e portadores textuais que os carregam, e, no centro, o sujeito que elabora, diante da recriação conciliatória de ambos, a originalidade e a articulação únicas das suas produções orais e escritas. É essa oportunidade de articulação singular dos elementos lingüísticos e gramaticais que constituem os gêneros discursivos que, talvez, faça a real diferença entre as crianças provenientes de meios letrados e as de meios iletrados, diante de suas produções orais. 
Ainda que se percebam os avanços teóricos nesse sentido, a prática escolar que se destaca no cotidiano das escolas ainda não se reflete. Nossa realidade educacional, em especial, a municipal e estadual, traz como forte preocupação a necessidade de se rever um processo de alfabetização que tem sido responsável por classes de $5^{\mathrm{a}}$ e $6^{\mathrm{a}}$ séries, com alunos não ou semi-alfabetizados, impedidos não só de comunicação e expressão e da inserção no mundo letrado como da compreensão e aproveitamento adequados às demais disciplinas / áreas trabalhadas até então. Caracterizam, nada mais, nada menos, alunos que estão dentro da escola - escola democrática pelas exigências teóricas - porém excluídos do processo de ensino-aprendizagem, dos objetivos mínimos que possam fazer deles cidadãos.

\section{Delimitação do tema e Objetivos}

As necessidades sinalizam para a prática do letramento como processo de apropriação dos usos sociais das atividades lingüísticas que configuram a escrita e a leitura, exigindo que se vá além da simples composição de palavras, frases ou textos; conforme atestam os Referenciais Curriculares Nacionais da Educação Infantil - RCNEI (BRASIL, 1998, p.121-122):

Pesquisas na área de linguagem tendem a reconhecer que o processo de letramento está associado tanto à construção do discurso oral como do discurso escrito. Principalmente nos meios urbanos, grande parte das crianças, desde pequenas, estão em contato com a linguagem escrita por meio de seus diferentes portadores de texto, como livros, embalagens, cartazes, placas de ônibus etc, iniciando-se no conhecimento desses materiais gráficos antes mesmo de ingressarem na instituição educativa, não esperando a permissão do adulto para começarem a pensar sobre a escrita e seus usos. Elas começam a aprender a partir de informações provenientes de diversos tipos de intercâmbios sociais e a partir das próprias ações, por exemplo, quando presenciam diferentes atos de leitura e escrita por parte de seus familiares, como ler jornais, fazer uma lista de compras [...], escrever uma carta para um parente distante, ler um livro de histórias etc. (grifo nosso)

Diante do quadro que se apresenta, este estudo tem como objetivo a delimitação do espaço de leitura de contos de fada e de uma seqüência de atividades que se utiliza da solicitação de paráfrases formuladas por crianças (reconto) como atividade que nos permita avaliar a retenção dos elementos lingüísticos a partir da leitura fonte, no caso dos contos de fadas lidos pelo professor.

Elemento de constituição do texto falado, segundo Hilgert (1996, p.132), a paráfrase é "um enunciado lingüístico que, na seqüência do texto, reformula um enunciado anterior, chamado de enunciado-origem ou matriz (M), com o qual mantém, em grau maior ou menor, uma relação de equivalência semântica".

Acreditamos que uma sequiência de atividades de paráfrases realizadas a partir de leituras feitas pelo professor pode propiciar um enriquecimento gradativo da linguagem oral das crianças investigadas. Aproveitando as concepções de Hilgert (1996), uma elaboração oral constantemente repensada, tendo em vista a relação de equivalência com o 
enunciado matriz, em muito tem a contribuir com a explicitação de estratégias de construção de textos orais.

A escolha da paráfrase como instrumento metodológico básico justifica-se em razão de considerarmos ser este procedimento senão o único, o mais viável como atividade que possibilite observar a retenção de elementos lingüístico- textuais presentes no texto-fonte.

Nesse sentido, Hilgert (1996, p.114-115) esclarece ainda mais:

Parafrasear é, dentro do processo de construção do texto, uma atividade lingüística de reformulação, por meio da qual se estabelece entre um enunciado de origem e um enunciado reformulador uma relação de equivalência semântica responsável por deslocamentos de sentido que impulsionam à progressividade textual.

Em decorrência do grande interesse das crianças da faixa etária selecionada (seis anos) por contos de fada, este foi o gênero discursivo selecionado. $O$ atrativo que esse gênero sustenta está, provavelmente, em tê-lo como resposta às necessidades das crianças desta fase: o envolvimento com o imaginário, a possibilidade de lidar com as emoções e os conflitos emergentes e, por que não dizer, com as questões éticas, contribuindo também, na construção da subjetividade e da sensibilidade das crianças. Sabemos ainda que, ao realizar com freqüência leituras de um mesmo gênero, o professor está propiciando às crianças oportunidades para que conheçam e dominem, cada vez mais, características próprias de cada um deles (BRASIL, RCNEI, 1998).

Mas não se trata de uma escolha que apenas seleciona o gênero; a qualidade da literatura também interfere como alimento à imaginação e ao prazer pela leitura, bem como possibilita a retenção de elementos lingüísticos presentes na(s) obra(s) selecionada(s).

Deparamo-nos, com frequiência, com publicações bastante diversas frente aos contos de fadas: temos os originais, enriquecidos em detalhes, cujo cuidado com a trama e aprofundamentos revela-se na atenção com a organização textual e lingüística, assim como temos contos apenas baseados em idéias originais, mas minimamente detalhados, ou seja, simplificados, no desenrolar das mesmas e que também revelam simplificações na organização textual e na formulação lingüística.

Cabe aqui diferenciar os rumos desta pesquisa de outras publicações referentes aos estudos dos contos de fadas e seus efeitos no imaginário das crianças. Bettelheim (1980) é um dos autores que muito tem contribuído com as repercussões psicológicas dos contos de fadas. No caso, a atenção volta-se como já foi dito, às retenções de elementos lingüísticos e ao desenvolvimento da oralidade mediante a solicitação de paráfrase das histórias ouvidas pelas crianças.

A pesquisa seleciona a faixa etária de 6 anos entendendo que a criança, neste momento, está construindo ativamente a sua oralidade. Tal é a ênfase nessa elaboração que os Referenciais Curriculares Nacionais da Educação Infantil (BRASIL, 1998, p.126) apontam essa construção da oralidade como objetivo da Educação Infantil desde a sua chegada à escola:

Nas inúmeras interações com a linguagem oral as crianças vão tentando descobrir as regularidades que as constitui usando os recursos que dispõem: histórias que conhecem, vocabulário familiar etc... Assim acabam criando formas verbais, expressões e palavras, na tentativa de apropriar-se das convenções da linguagem. 
Serão selecionadas crianças da rede pública de ensino em detrimento à rede particular, pelas menores oportunidades de acesso à leitura desse gênero e outros. No caso, o estudo feito junto às escolas da rede pública municipal, pretende selecionar no início do ano letivo, quatro crianças que em relação ao grupo apresentarem oralidade reduzida no que se refere aos aspectos selecionados para análise, para que as mesmas participem, individualmente, da sequiência de atividades proposta.

O trabalho com crianças de faixa etária de 6 anos da rede pública municipal de ensino de São José dos Campos fazendo uso de dois tipos de contos de fada ( de diferentes características de enriquecimento textual e lingüístico) que logo em seguida serão parafraseados por elas, permitirá analisar os elementos retidos, por eles, nestas paráfrases, bem como os efeitos dessas retenções na construção da oralidade.

Um segundo objetivo refere-se à análise dessas diferentes características de organização textual e lingüística no que diz respeito à construção da oralidade.

Objetiva-se, portanto, a partir da análise da evolução das paráfrases feitas pelas crianças imediatamente após aplicar a seqüência de atividades de leitura (que inclui dois contos de fadas enriquecidos e dois simplificados quanto à organização textual e lingüística), verificar os avanços na oralidade no que se refere à incorporação de elementos de formulação do texto escrito. Bem como, busca-se comparar as características dessas retenções em função das diferenças de organização supracitadas que os textos carregam.

Assim sendo, procuraremos responder as seguintes questões:

Quais características do texto-fonte apresentado pelo professor (no que se refere ao detalhamento, seleção lexical, estrutura textual, elementos coesivos, bem como seqüências lógica e temporal) são incorporados ao texto oral pela criança na atividade parafraseadora?

Como se dá e o que caracteriza o caminhar das crianças investigadas frente à apropriação da linguagem formal presentes nos textos orais a partir desta estratégia?

Que diferenças se observam nos resultados decorrentes da aplicação dos mesmos contos com formulações diversas, ou seja, quais as características das formulações de paráfrases originadas do texto-fonte detalhado em comparação às originárias de textos simplificados?

\section{Procedimentos Metodológicos}

A escolha da paráfrase como instrumento metodológico básico se justifica em razão de considerarmos ser este procedimento senão o único, o mais viável enquanto atividade que possibilite observar a retenção de elementos de natureza diversa presentes no textofonte.

Nesse sentido Hilgert (1993, p.114) esclarece ainda mais:

Parafrasear é, dentro do processo de construção do texto, uma atividade lingüística de reformulação, por meio da qual se estabelece entre um enunciado de origem e um enunciado reformulador uma relação de equivalência semântica responsável por deslocamentos de sentido que impulsionam à progressividade textual.

São Fávero e Urbano (apud FAVERO, 2002) que esclarecem: todo e qualquer texto tem uma multivocidade inerente (igual a muitas leituras); o enunciador faz sempre uma 
interpretação do texto fonte e não só o reorganiza de forma diferente como também o interpreta com base no texto derivado no momento em que produz a paráfrase.

Há de se distinguir, segundo Fávero (2002) a paráfrase de repetição, pois enquanto na primeira prevalece a criatividade, a repetição caracteriza-se pelo automatismo.

Neste contexto, ainda segundo Eco (1977), utilizar, por vezes, algumas palavras imutáveis no sentido e na caracterização do texto pode ser útil e até inevitável; que também pode nos levar a concluir que a incorporação de um vocabulário mais rico está em constante exercício.

O estudo envolverá a aplicação do procedimento de paráfrase com quatro crianças que, no início do ano letivo, demonstrarem em relação ao grupo, uma oralidade reduzida no que se refere aos aspectos selecionados para análise: detalhamento, seleção lexical, estrutura textual, elementos coesivos e seqüência lógica e temporal. O procedimento será aplicado individualmente em uma sequiência de atividades que prevê a solicitação da paráfrase iniciando pelos dois contos de fadas simplificados na sua organização textual e lingüística e seguindo pelos dois outros enriquecidos nessas características, para assim verificar, com maior clareza, os objetivos básicos: as retenções lingüísticas na construção da oralidade e seu caminhar evolutivo a partir da sequiência de atividades proposta, bem como as diferenças dessas retenções que são conseqüentes às diferentes escolhas de organização dos textos.

Podemos, logo em seguida, definir as seguintes etapas do processo de pesquisa:

a) No que se refere à continuidade da fundamentação teórica:

Além da seleção e resenha bibliográfica adequadas que permitam a redação do quadro teórico, serão selecionados quatro contos de fadas em busca de diferenças textuais evidentes, sendo dois deles simplificados quanto à organização textual e dois outros enriquecidos nesse sentido.

b) No que se refere à aplicação dos procedimentos de paráfrase:

b.1) $1^{\text {a }}$ etapa - Leitura de cada um dos dois primeiros contos de fadas simplificados quanto à organização textual

* Solicitação de cada paráfrase

* Gravações das produções parafrásticas.

b.2) $2^{\mathrm{a}}$ etapa - Leitura de cada um dos dois últimos textos enriquecidos quanto à organização textual

* Solicitação de cada paráfrase

* Gravações das paráfrases produzidas oralmente.

Em seguida procederemos na seguinte ordem:

Análises e redação:

Análise das retenções lingüísticas dos materiais coletados nas duas etapas (análise por criança)

Análise comparativa da evolução das retenções das quatro crianças frente à sequiência de atividades aplicada

Análise comparativa das diferentes retenções lingüísticas provenientes das diferenças de organização textual.

Após a elaboração de um quadro conclusivo, procederemos à redação final do trabalho monográfico. 


\section{Pressupostos Teóricos}

\section{A leitura formadora: uma ênfase à interação}

Quando se tem como propósito a construção/avanços da oralidade por intermédio de atividades parafraseadas, cabe buscar conhecer aspectos da linguagem e sua produção, bem como buscar compreender os mecanismos e intervenções que possam produzir significados aos contextos de linguagem e leitura:

\section{1) Linguagem e participação social}

O domínio da língua e sua estreita relação com a possibilidade plena de participação social, que acaba por atribuir à escola a responsabilidade de garantir aos alunos acesso aos saberes lingüísticos necessários para o exercício da cidadania é fato inquestionável. Assim, cabe destacar que a responsabilidade aumenta quanto menor for o grau de letramento das comunidades em que vivem os alunos.

Há de se destacar mais especificamente o papel do professor como planejador de intervenções e atividades que insiram as crianças na prática do mundo letrado. Esse planejamento, por sua vez, exige um repensar teórico sobre as questões da linguagem e seu processo de construção.

Se produzir linguagem significa produzir discursos, embora num processo de interlocução nem sempre se faça escolhas conscientes, é certo que essas escolhas acontecem e, além disso, trazem implícitos: o gênero no qual o discurso se realizará, a relação de procedimento, de estruturas e também, a seleção de recursos lingüísticos. Tratase de uma sequiência verbal construída por um conjunto de relações que se estabelecem a partir da coesão e coerência: conjunto esse que chamamos de textualidade.

O discurso se manifesta lingüisticamente por meio de textos e estes, como resultantes de atividades discursivas, se relacionam uns com os outros (produzindo textos e outros textos: relação intertextualidade).

É neste contexto que os PCN (BRASIL, 1998, p.26), oferecem grande contribuição na questão da linguagem relacionada ao trabalho com os textos discursivos:

Todo texto se organiza dentro de um determinado gênero. Os vários gêneros existentes, por sua vez, constituem formas relativamente estáveis de enunciados, disponíveis na cultura, caracterizados por três elementos: conteúdo temático, estilo e construção composicional. Pode-se ainda afirmar que a noção de gêneros refere-se a "famílias" de textos que compartilham algumas características comuns, embora heterogêneas, como visão geral da ação à qual o texto se articula, tipo de suporte comunicativo, extensão, grau de literariedade, por exemplo, existindo em número quase ilimitado.

A contribuição dada pela elucidação da idéia de que os discursos não acontecem no vazio e que trazem subjacentes gêneros discursivos que lhes garantem textualidade é, ao 
nosso ver, o princípio maior que nos remete ao trabalho com a exploração das características desses gêneros como base da construção de uma oralidade que venha assessorar, graças à apropriação dos recursos lingüísticos subjacentes, a produção escrita que temos como consequente.

Parece que as elaborações na oralidade repercutindo nas produções escritas como consequiência é um sistema que se auto-alimenta e se fortalece. Assim, como diz Tolchinsky, 1990 (apud SÃO PAULO, 1993, p.41), as crianças:

[...] aprendem a utilizar a escrita como artefato intertextual, um fim em si mesmo que promove o desenvolvimento cognitivo. A linguagem escrita é um fato, um instrumento - e o seu domínio não significa apenas a melhoria das habilidades comunicativas, mas a ampliação do próprio processo de pensamento.

Neste contexto, o trabalho com a leitura desses textos (seja ela, de início, proferido pelo professor e/ou mais tarde, realizado pela criança), é um tema relevante nesse processo.

\section{2) Leitura em uma abordagem dinâmica}

Entende-se atualmente leitura como um processo dinâmico onde, com base nos conhecimentos prévios, o leitor realiza um trabalho ativo de interação com o texto a ponto de construir um significado que é único, singular, pois prevê a interação dos seus objetivos, do conhecimento com o assunto, sobre o autor e as informações do texto (ANGELIS e SILVA, 2000).

A ação do leitor sobre o texto cabe ressaltar, não recai somente sobre as letras nele presentes. As informações advêm de inúmeras informações visuais que interagem na representação do mesmo: as ilustrações, o "formato" que determina sua estrutura textual, as características de seu portador (capa, formato, organização), podem muito contribuir para a diferenciação do gibi, de um livro, de um jornal e que são determinantes, decisivos na apreensão do significado do texto.

No entanto, a prática escolar tende ainda hoje a buscar por padronização desse processo tão único/pessoal. Verificam-se leituras por meio de provas, exigindo-se quase sempre que os alunos reconheçam a resposta "correta", repitam dados dos livros e respondam questões cujas seqüências de respostas correspondem à seqüência das informações do texto. Quase sempre a imposição de um único livro parece garantir a uniformização das perguntas e respostas (ANGELIS e SILVA, 2000).

Percebamos que essa homogeneização busca garantir a predominância da expectativa/visão do professor que impõe a artificialidade aos aspectos de ação criativa do aluno sobre todo e qualquer material escrito.

As concepções de leitura recaem, segundo Baberger e Coracini (1995; apud ANGELIS e SILVA, 2000, p.115), sobre uma postura interacionista que aponta a leitura como uma confrontação crítica com o texto e as idéias do autor, ou seja, é o sujeito 
(heterogêneo) e não o texto que determina as leituras. "Ele é o ponto de partida e o de chegada no processo de aprendizagem da linguagem".

Neste contexto, é Jolibert (1994, p.12-14), que questiona se é preferível que a escola seja um meio onde tudo é pensado e gerado pelo adulto ou por todos aqueles (crianças e adultos) que constituem a coletividade escolar.

E acrescenta no que se refere à leitura:

Nas sessões habituais de leitura que consistem, para as crianças, em decifrar a frase do dia que elas mesmas ditaram previamente, ou codificaram, quem é que faz as perguntas? Dá as instruções? Faz referência ou não às "etiquetas"? Pede para observar o que é igual ou não? O professor, sempre o professor... Qual a atividade que resta às crianças? Certamente não a de procurar um sentido na referida frase: elas a conhecem, elas a ditaram. Não, são sessões cuja meta não é ensinar a ler às crianças.

Assim, não desaparece o papel do professor, pelo contrário ele intervém ajudando as crianças a interrogarem o sentido, proporcionando sentido de leituras efetivas e diversificadas, ajudando a utilizar os instrumentos progressivamente elaborados pela turma e elucidando suas próprias estratégias de leitura. É dessa forma que o ler deve partir de uma expectativa real (necessidade/prazer), numa situação verdadeira de vida.

Como sugestão de autonomia, apresentado por Jolibert (1994), tendo em vista a leitura de sujeitos cooperativos com objetivos comuns (necessidade confirmada por Kleiman, 1995), concebe a leitura numa perspectiva interativa e ativa e prevê a prática de trabalho com os diversos gêneros discursivos solicitados pelo cotidiano. Assim, temos fundamentalmente, para os propósitos desta pesquisa, a exploração do real dos gêneros discursivos como base na construção da oralidade, uma vez que concebe o ato de ler como cruzamento de vários eixos, dentre eles: “- primeiramente, o conhecimento do próprio funcionamento do ato textual e dos processos de leitura; - o conhecimento do funcionamento da língua escrita" (JOLIBERT, 1994, p.11).

E, dessa forma, torna-nos possível a idealização de um processo que vai em busca do alfabetizar letrando.

\section{2) Alfabetização e letramento}

É na segunda metade da década de 80, há cerca de 29 anos, que o termo letramento vai se infiltrando nas publicações e conversas sobre alfabetização de especialistas da área. A palavra não está direcionada e não podemos datar com precisão quando e onde foi utilizada pela primeira vez. De acordo com Soares (2001, p. 33), Kato foi a primeira pessoa a utilizá-la em seu livro "No mundo da escrita: uma perspectiva psicolingüística", de 1986: "Acredito que a norma-padrão, ou língua falada culta é conseqüência do letramento, motivo por que, indiretamente, é função da escola desenvolver no aluno o domínio da linguagem falada institucionalmente aceita (...) 
A palavra letramento não é, como se vê, definida pela autora e, depois dessa referência, é usada várias vezes no livro; foi provavelmente, essa a primeira vez que a palavra letramento apareceu na língua portuguesa - 1986 .

Soares (2001, p.18) aponta o sentido do letramento como:

(...) palavra que criamos traduzindo "ao pé da letra" o inglês 1 iteracy: letra- do latim littera, e o sufixo- mento, que denota o resultado de uma ação [...] letramento é, pois, resultado de ação de ensinar ou de aprender ler e escrever: o estado ou a condição que adquire um grupo social ou um indivíduo como consequiência de ter se apropriado da escrita.

E, ainda, acrescenta e destaca a amplitude do termo letramento (confrontado com o termo alfabetização) uma vez que envolver-se nas práticas sociais de leitura e escrita é mais que adquirir a tecnologia de ler e escrever e tem consequiências sobre o indivíduo alterando seu estado ou condição em aspectos sociais, psíquicos, culturais, políticos, cognitivos, lingüísticos e até econômicos. Se analisarmos, do ponto de vista social, a introdução da escrita em um grupo até então ágrafo produz efeitos em todos os aspectos citados, modificando a visão de mundo e a participação social que caracterizam a condição de letramento.

Percebe-se que, quando se emergem novas necessidades e idéias, dá-se um novo sentido às velhas palavras ou se criam novas:

Antes o nosso problema era apenas o do "estado ou condição de analfabeto" - a enorme dimensão deste problema não nos permite perceber esta outra realidade, o " estado ou condição de quem quer ler ou escrever", e, por isso, o termo analfabetismo nos faltava, o seu oposto alfabetismo ou letramento - não nos era necessário. Só recentemente esse oposto tornou-se necessário, porque só recentemente passamos a enfrentar essa nova realidade social em que não basta ler e escrever, é também preciso fazer uso do ler e escrever, saber responder as exigências de leitura e escrita que a sociedade faz continuamente - daí o recente surgimento do termo letramento (que como já foi dito, vem se tornando de uso corrente, em detrimento do termo analfabetismo). (SOARES, 2001, p.20)

Assim o termo letramento surgiu de uma nova necessidade social e adquiriu força e demonstrou-se emergente: a de ir além da decifração, da composição de palavras, da mera junção de sinais gráficos tendo em vista a associação letra-som. Se a esta idéia caberia o termo alfabetização, foi necessário demonstrar, a partir de um termo mais reflexivo e abrangente, essa nova preocupação social.

Não se pode dizer que a pessoa letrada passa a ter uma outra condição social ou cultural diante dessa aquisição. Não se trata de mudar de classe social, mas sim de lugar social: o seu modo de viver em sociedade, sua relação com os outros, com o contexto e com os bens culturais (SOARES, 2001, p. 31).

A autora traz também a tona uma nova conseqüência de inserção do indivíduo no mundo letrado: o letrado conquista avanços cognitivos e lingüísticos. O indivíduo, após aprender a ler e a escrever e se inserir no mundo letrado, evidencia uma forma de pensar diferente e um convívio com a língua escrita que traz conseqüências no seu uso de linguagem oral, nas estruturas da língua. 


\section{1) Como diferenciar o apenas alfabetizado do letrado?}

Pode-se dizer que ler e escrever são conjuntos de habilidades e comportamentos que se compõem ao longo de um continuum. Uma pessoa pode ser capaz de ler um bilhete e não ser capaz de ler um romance. Também ser capaz de escrever uma carta, mas, não um texto argumentativo. A partir de que ponto desse continuum a pessoa pode ser considerada letrada, no que se refere à leitura e à escrita? O que separaria o indivíduo letrado do não letrado?

Não temos respostas definitivas nesse sentido, mas há necessidade de perceber que o termo surgiu com base em novas concepções e necessidades do mundo moderno.

O letramento na dimensão individual requer, em primeiro lugar, a análise das diferenças entre a habilidade de ler e escrever. Na leitura, ela vai desde a habilidade de decodificar palavras escritas até a capacidade de compreender textos escritos. Estende-se da habilidade de traduzir sons em sílabas sem sentido, às habilidades cognitivas e metacognitivas: a capacidade de captar significados, interpretar idéias e eventos, analogias, como, linguagem figurada, a habilidade de se fazer previsões iniciais sobre um assunto, refletir sobre o significado do que foi lido.

Neste contexto, diversos portadores textuais estão em jogo: literatura, rótulos, cardápios, sinais de trânsito, receitas, sinalização urbana, jornais, listas, catálogos etc...

$\mathrm{Na}$ escrita também englobamos habilidades diversas que incluem: caligrafia, ortografia, pontuação, habilidade de transcrever a fala, de organizar as idéias, de relacionálas, de selecionar informações para um determinado público leitor etc. todas elas aplicadas, também, diferencialmente à produção de diversos materiais escritos.

Percebemos o conceito de alfabetização sempre atrelado aos lugares, ao tempo e ao contexto cultural, ideológico e político. Scribner (apud SOARES, 2001, p. 79) define muito bem a questão quando destaca em certo momento, a habilidade de escrever o próprio nome era a comprovação do letramento; hoje, em algumas partes do mundo, a habilidade de memorizar um texto sagrado é a principal demanda de letramento. $\mathrm{O}$ letramento não tem uma essência estática nem universal .

A preocupação dos países de primeiro mundo não está centrada na alfabetização e sim nos níveis de letramento que ainda são baixos. Talvez estejamos todos preocupados com a resposta a uma questão maior:

- Quais são as condições para que o aprender a ler e escrever seja algo que tenha realmente sentido, uso e função para as pessoas, ou seja, como alcançar um caminho que conduza a uma alfabetização de qualidade atrelada ao letramento?

\section{A narrativa oral e a paráfrase}

\subsection{Narrativa oral}

Analisar a conversação talvez seja ter em vista a prática social mais comum no cotidiano do ser humano. É no espaço da conversação que se constrói as identidades sociais contextualizadas. Pareceu-nos claro que o desempenho lingüístico na fala não se serve 
apenas de aspectos de estrutura gramatical e lexical da língua, mas lança mão de recursos variados que envolvem o contexto da ação e interação social presentes nestes atos.

Todo evento de fala acontece em um ambiente extralingüístico: a situação, o momento e as circunstâncias que o texto acontece contextualizam uma interação verbal centrada em uma tarefa comum, envolvendo experiências mútuas.

Esta perspectiva ultrapassa a análise das estruturas e atinge processos cooperativos presentes na atividade conversacional, o que evidencia que ela é um fenômeno anárquico e aleatório, mas altamente organizado e passível de rigor científico. (MARCUSCHI, 2001)

Há aí, portanto, um espaço rico de estudo (Análise de Conversação) e compreensão que vai além de gramática e de léxico e volta o olhar para toda essa coordenação de recursos verbais e não verbais que, como bem coloca o autor (2001, p.7), pretende chegar a um sistema de regras "livres de contexto" e "sensíveis ao contexto" onde a formalidade submete-se ao controle dos falantes em cada caso.

No que se refere à conversação Sacks, Schegloff e Jefferson (1974; apud Marcuschi, 2001, p. 17) montaram um modelo elementar, que se apoia no sistema de tomada de turno, baseado na regra universal que a conversação exige que "fale um de cada vez" e há técnicas que operam essa preocupação. Trata-se do fator disciplina das conversações, regra básica válida para a maioria das línguas e culturas.

Vale ressaltar que a troca de turno pode dar-se a qualquer momento em que ocorra um lugar relevante para a sua transição (Marcuschi, 2001, p.18). E ainda acrescenta: "o mais difícil não é definir quando há ou não uma mudança de turno e sim saber o que determina essa mudança e qual é o momento propício para ela ocorrer".

Segundo Marcuschi (2001, p. 20-23):

O que se tem claro é que a tomada de turno obedeceu a um mecanismo de regras que envolve: o falante corrente escolhe o próximo; o falante corrente pára e o próximo obtém o turno (Nesses casos, o número de falantes podem gerar conversações paralelas).

Fatores não verbais também influenciam: olhar fixo, hesitações (tipo Ah, eh, silêncio), pausas, podem ser marcadores significativos nas tomadas de turno quando não funcionam como um pedido de socorro.

Outros elementos como entonação baixa podem causar o mesmo efeito.

Muitas vezes o sistema/mecanismo de reparação e correção tão frequentes no percurso da conversação acaba por influenciar as transições de turno em função da posição que ocupam; Ex.: correção pelo outro e iniciadas pelo outro (tendo o outro como ouvinte) acabam por configurar o turno subsequente; auto correção iniciadas pelo outro ou seja, a retomada da palavra pelo falante que cometeu a falha configuram em geral um $3^{\circ}$ turno. 
Embora a troca de falantes aliada ou não às falhas de construção possa ser um fator relevante para o aparecimento dos marcadores conversacionais, Marcuschi (2001, p. 61 74) prevê outras situações onde a incidência dos mesmos se torne imprescindível:

podem ser iniciadores ou finalizadores da unidade comunicativa como substituto conversacional para a "frase" e diferenciando dos turnos. Ex.: iniciais (olha, mas eu...) e finais (né", certo")

Os marcadores explicitados acima definem muito dos sinais do falante que orientam o ouvinte. No entanto, como se trata se uma interação centrada e constante, estão presentes sinais do ouvinte que orientam o falante e que ocorrem geralmente em sobreposição demonstrando concordância, discordância, indagações que encorajam ou solicitam esclarecimento, promovendo exploração adicional ao tópico.

A naturalidade da passagem de um tópico para outro é a garantia de uma conversação fluente. Ou seja, é a armação do quadro tópico que organiza a conversação: "dois turnos contíguos que apresentam o desenvolvimento do mesmo conteúdo sequenciam o mesmo tópico, e dois turnos que não sequenciam o mesmo conteúdo constituem uma mudança de tópico". (Marcuschi, 2001, p. 80) Entre a continuidade e a mudança temos a possibilidade da quebra de tópico.

\section{2 Paráfrase}

Entende-se por paráfrase, segundo Hilgert (1996), um enunciado lingüístico que na sequiência do texto reformula um enunciado-origem ou matriz, com o qual mantém relação maior ou menor, de equivalência semântica.

Ainda segundo o autor, "prevê-se uma relação paradigmática, podendo ocupar o mesmo lugar sintático da matriz no contexto em que está inserida" (p. 132-144).

A passagem de matriz para a paráfrase pode demonstrar dois tipos de movimento semânticos básicos:

- a especificação - quando o movimento semântico da matriz para a paráfrase vai do geral para o específico, (caminho de condensação sintática-lexical, de uma formulação mais simples)

- a generalização - no caso, o envolvimento da matriz para a paráfrase vai do específico para o geral, a caminho de expansão sintático-lexical e de um enunciado mais complexo que a matriz.

Apesar da variação lexical, a dimensão formal da matriz pode ser mantida. Neste contexto, as paráfrases elevam mais que amplitude e especificação trazem subjacentes funções específicas. Enquanto as paráfrases expandidas têm função definidora, ou seja, define termos abstratos mencionados na matriz a condensação parafrástica assume a função de resumo, sintetizando informações apresentadas na matriz.

Há ainda as paráfrases paralelas que, do ponto de vista formal, só diferem dos seus enunciados de origem por variações lexicais. Acabam por especificar o termo ou a expressão parafraseada, buscando adequação vocabular.

Ex. - Problemas de saúde?

- Problemas de tiróide...

É Hilgert (idem, p.143) que tão bem esclarece: 
Podemos dizer que as paráfrases têm, na constituição do texto falado, a função de garantir a intercompreensão conversacional (...) explicitando, especificando, resumindo ou denominando informações da matriz.

À luz dessas concepções e do caráter reformulador, Hilgert (1993) destaca a paráfrase como responsável pelos deslocamentos de sentidos que impulsionam à progressividade textual. É neste contexto que o autor destaca novas funções às paráfrases que em nenhum momento perdem a identidade significativa com a matriz (seja ele de equivalência semântica - forte ou fraca) - chegando a conferir um deslocamento de sentido do texto:

- Adjacentes - têm função local no desenvolvimento do texto;

- Não adjacentes - estruturam a conversação num nível mais abrangente.

No presente trabalho, esperamos que as reflexões anteriores destaquem ao leitor o papel da paráfrase na contribuição do texto oral e a compreensão da fundamentação e sua relevância diante dos objetivos que a pesquisa propõe.

Como bem afirma Hilgert (1993, p.126): "Identifico, em suma, o parafraseamento com uma atividade de constituição textual, a que o falante recorre para reformular etapas do desenvolvimento de sua própria formulação textual".

\section{Bibliografia}

ANGELIS, Sônia A.; SILVA, Marlene M. C. Leitura Recreativa: uma abordagem dinâmica. IN: Revistada da Pedagogia. PesquisaAção. São Paulo: UNITAU, v.2, ano 2, 2000, p. 13-117.

BRASIL, Ministério da Educação e Desporto. Secretaria da Educação do Ensino Fundamental. Referencial Curricular Nacional para a educação infantil. Brasília: MEC/SEF, 1998. 3v. em 3.

BRASIL, Ministério da Educação. Secretaria da Educação Fundamental. Parâmetros Curriculares Nacionais: Língua Portuguesa. 3.ed. Brasília: A Secretaria, 1998. 10v. em 2.

CARVALHO, Adriana Cintra de. Desenvolvimento da competência genérica da prática de leitura de crianças não alfabetizadas como parte do processo de letramento. Dissertação de Mestrado. Programa de Lingüística Aplicada- Universidade de Taubaté, SP, 2003.

ECO, Umberto. Como se faz uma tese? 13 ed. São Paulo: Ed. Pesrpectiva, 1997, p.128-129.

FÁVERO, Leonor L. Coesão e coerência textuais. 9 ed. São Paulo: Ática, 2002. (Série Princípios).

FERREIRO, Emília. Reflexões sobre alfabetização. São Paulo: Cortez, 1990. (Coleção Polêmicas do nosso tempo)

HILGERT, José Gaston. A paráfrase: um procedimento de constituição do diálogo. Tese de doutorado. FFLCH/USP, 1993.

As paráfrases na construção do texto falado: o caso das paráfrases em relação paradigmática com suas matrizes. IN: KOCH, Ingedore G. V. (org.) Gramática do Português Falado. Campinas, 1996, p.131-147. 
JOLIBERT, J. Formando crianças leitoras. Porto Alegre: Artemed ed., 1994.

KLEIMAN, Ângela B. (org.) Os significados do letramento. São Paulo: Mercado das Letras, 1995.

MARCUSCHI, Luiz A. Análise de conversação. 5 ed. São Paulo: Ática, 2001. (Série Princípios).

SÃO PAULO. (Estado) Secretaria da Educação. Coordenadoria de Estudos e Normas Pedagógicas. Ler e escrever: um grande prazer: São Paulo: SE/CENP, 1993, p.41.

SILVA, Gustavo P. P. Estruturas Sintáticas do Português. Rio de Janeiro: Vozes, 1983, p.29-41.

SOARES, Magda B. Letramento: um tema em três gêneros. 2 ed. Belo Horizonte: Autêntica, 2001. 